\title{
A Study on Resting Heart Rate and Heart Rate Variability of Athletes, Non-athletes and Cricketers
}

\author{
Subhashis Biswas \\ Department of Sports Science and Yoga, Ramakrishna Mission Vivekananda Educational and Research Institute, Belur Math, India \\ Email address: \\ nayanavi.96@gmail.com

\section{To cite this article:} \\ Subhashis Biswas. A Study on Resting Heart Rate and Heart Rate Variability of Athletes, Non-athletes and Cricketers. American Journal of \\ Sports Science. Vol. 8, No. 4, 2020, pp. 95-98. doi: 10.11648/j.ajss.20200804.13
}

Received: July 29, 2020; Accepted: August 21, 2020; Published: December 4, 2020

\begin{abstract}
Resting heart rate (RHR) is a primary marker to understand the overall physical state of an individual. Rhythmic changes in heart rate (HR) at any given point reflect the complex interactions between parasympathetic and sympathetic nerves system. Assessment of workload through HR can be confusing unless RHR is known. RHR \& heart rate variability (HRV) at rest are important to justify training load, recovery and adaptation in sports. The study was carried out to explore the values of RHR and HRV parameters of cricketers, athletes and non-athletes of West Bengal. Forty three male volunteers with a mean age of $20.2 \pm 2.1$ years were selected for the study. Five minutes R-R intervals were recorded during resting state in the supine position. Mean HR, SDNN, and rMSSD of cricketers has been found to be $57 \pm 5 \mathrm{bpm}, 54.5 \pm 15.7 \mathrm{~ms}$, and $66.8 \pm 21.6 \mathrm{~ms}$ respectively. No significant difference found in SDNN and rMSSD of three groups but a significant $(p<0.05)$ difference has been observed in RHR of cricketers. A low resting heart rate, a kind of bradycardia, has been found in the cricketers.
\end{abstract}

Keywords: Resting Heart Rate, Heart Rate Variability, Time Domain Analysis, Cricket, Athletics

\section{Introduction}

Heart rate (HR) is a physiological indicator determined by the pacemaker activity of the sinoatrial node (SA node). The SA node exhibits automaticity, that is determined by spontaneous changes in Sodium $\left(\mathrm{Na}^{+}\right)$, Potassium $\left(\mathrm{K}^{+}\right)$, Chloride $\left(\mathrm{C}^{-}\right)$and Calcium $\left(\mathrm{Ca}^{++}\right)$ions [1]. The two branches of the Autonomic nervous system tax on the SA node and determine HR. An increase in HR generally indicates an increase in the demand of blood $\mathrm{O}_{2}$ for a particular organ or many organs. HR at rest exhibits an oscillatory pattern in synchronicity with the respiratory cycle [2]. During inhalation, HR increases due to stimulation of sympathetic nerve, inhibition/withdraw of parasympathetic efferent via the vagus nerve and blood pressure decreases due to the increase of intra-thoracic diameter.

Resting heart rate (RHR) may be defined as, without any external or internal influence, rate of contraction of heart to maintain basal metabolic rate at complete rest. RHR depends on type of sports. Regular physical activity helps to reduce RHR [3]. HR at rest depends on increases in parasympathetic tone or decrease in beta-adrenergic stimulation or change in end diastolic volume in the intrinsic HR mechanisms [3]. It is well known that high RHR is associated with increased cardiovascular risk in general populations, possibly due to sympathetic over-activity or elevated blood pressure (BP). Nowadays, RHR along with HRV is considered as a very effective way to prevent serious mistakes in training [4, 5]. A simple inspection of RHR can indicate training adaptation when HRV is trending positively [4]. According to an experimental study of Buchheit et al., Improvements in maximal aerobic running speed largely $(\mathrm{r}=-0.73)$ correlated with increases in resting HRV [5]. Moderate training loads increase aerobic fitness, as well as HRV and high levels of training load reduce HRV [6]. Prolonged high level of training induces stress regeneration imbalance that increases fatigue and reduces performance [3]. Generally, low HRV score at rest indicates that the body is under stress from definite internal (psychological events) or external (exercise) stress $[7,8]$. On the other side, a high HRV score indicates that the body has a strong ability to tolerate definite internal and external stress $[3,4,7]$. From above point of view RHR \& HRV at rest are important to justify training load and adaptation in sports [5]. Thus the study was carried out to explore the values of RHR and HRV parameters of cricketers, athletes and non-athletes of West Bengal. 


\section{Methodology}

\subsection{Participants}

Forty three male volunteers were selected for the study. Three volunteers were excluded from the study due to incomplete and low quality of data. The volunteers involved 14 athletes, 11 non-athletes, and 15 cricketers. The volunteers who represent their district in a state competition were selected for the study. Volunteers not involved in active physical training were selected as non-athletes.

\subsection{Experimental Overview}

All volunteers were familiarized with the test protocol. The volunteers did not take any food, at least, one hour before the test. The volunteers did not take any medicines or other drugs before 48 hours of data collection. All the volunteers were free from any cardiovascular disease as was confirmed from the ECG reports. All volunteers were informed about the study content and their written consent was collected. Short-term (5-10 $\mathrm{min}) \mathrm{HR}$ at resting condition in supine position was monitored for evaluate RHR [2, 3]. HR variation at rest depends on several physical, physiological, psychological and environmentally independent parameters. So, during the period of data collection, these parameters were monitored and recorded $[2$, $5]$.

\subsection{HR Data Analysis}

Polar heart rate monitor (Polar V800 smart watch along with chest strap and $\mathrm{H} 7$ Bluetooth sensor) was used for continuous recording of R-R intervals. After 10 minutes of rest in a supine position, five minutes $\mathrm{R}-\mathrm{R}$ intervals (along with two minutes of stabilization period) were recorded during resting state in the supine position [2]. The volunteers were allowed to breathe naturally. The time of data recording was in between 11:30 a.m. to 3:30 p.m. in a quiet room. Polar flow sync app was used to export the raw data. HRV analysis was done using the Kubios HRV Standard software (3.3.1). The time domain parameters such as Standard deviation of all NN intervals (SDNN), Root mean squared sum of successive NN intervals (rMSSD) and the percentage of the difference between adjacent $\mathrm{NN}$ intervals differing more than 50 milliseconds (ms) (pNN50\%) were analysed in the study [9].

\subsection{Statistical Analysis}

Anderson-Darling Normality Test was done to understand the distribution pattern of the independent individual-centric data set. According to the nature of the distribution pattern, parametric tests were applied. One way single factor ANOVA along with Tukey-Kramer test (post hoc test) was done to explore differences between multiple group means using Gnumeric Spreadsheet. The level of significance was set at $\alpha$ $\leq 0.05$.

\section{Results}

Table 1. The basic physical and anthropometric characteristics of three groups.

\begin{tabular}{llll}
\hline Parameters & $\begin{array}{l}\text { Cricketers } \\
(\mathbf{N}=\mathbf{1 5})\end{array}$ & $\begin{array}{l}\text { Athletes } \\
(\mathbf{N = 1 4 )}\end{array}$ & $\begin{array}{l}\text { Non-athletes } \\
(\mathbf{N}=\mathbf{1 1})\end{array}$ \\
\hline Age $($ year $)$ & $18.9 \pm 1.9$ & $20.3 \pm 4.4$ & $20.8 \pm 1.9$ \\
Height $(\mathrm{m})$ & $1.691 \pm 0.251$ & $1.665 \pm 0.540$ & $1.718 \pm 0.374$ \\
Mass $(\mathrm{kg})$ & $58.6 \pm 2.8$ & $54.7 \pm 9.7$ & $71.5 \pm 8.3$ \\
BMI $\left(\mathrm{kg} / \mathrm{m}^{2}\right)$ & $20.48 \pm 0.70$ & $19.61 \pm 2.49$ & $24.17 \pm 2.03$ \\
\hline
\end{tabular}

No significant difference has been found in age and height among three groups but a significant difference has been found in the predicted BMI between non-athletes group and other two counterparts.

Table 2. Quantitative table values of time domain parameters.

\begin{tabular}{lllll}
\hline Groups & $\begin{array}{l}\text { RR intervals } \\
(\mathbf{m s})\end{array}$ & SDNN (ms) & rMSSD (ms) & pNN50 (\%) \\
\hline Cricketers & $1059.1 \pm 75.3$ & $54.5 \pm 15.7$ & $66.8 \pm 21.6$ & $45.8 \pm 15.9$ \\
Athletes & $931.6 \pm 91.6$ & $49.5 \pm 18.4$ & $59.2 \pm 23.7$ & $35.1 \pm 19.2$ \\
Non-athletes & $820.9 \pm 81.0$ & $43.8 \pm 19.3$ & $44.1 \pm 17.6$ & $24.7 \pm 15.9$ \\
\hline
\end{tabular}

Table 2 represents pooled mean of 4494 R-R intervals of 14 athletes, 4265 RR intervals of 15 cricketers and $4030 \mathrm{RR}$ intervals of 11 non-athletes volunteers.

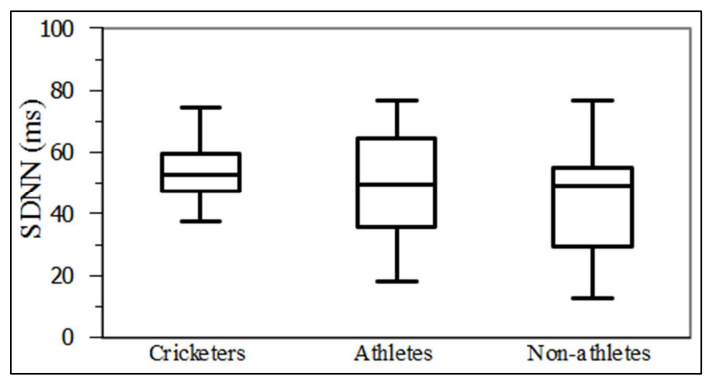

Figure 1. Over all HRV of three different groups

SDNN value of three different groups has been plotted in the figure 1. In case of cricketers groups, a high and compact quartile range displays in above noted figure but no significant difference has been found in SDNN value of three groups.

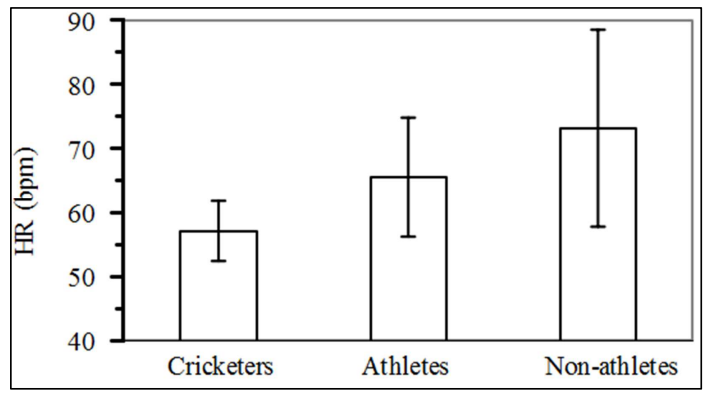

Figure 2. HR variation of three different groups at rest.

Average inter-beat variation of RR intervals has been found in the non-athletes group (43 ms), cricketers group (59 $\mathrm{ms})$ and athletes group $(60 \mathrm{~ms})$. Mean and range of HR of the three groups (cricketers, athletes and non-athletes) have been 
found to be $57 \pm 5 \mathrm{bpm}$ and $52-65$ beats; $66 \pm 9 \mathrm{bpm}$ and 59 -74 beats and $72 \pm 13 \mathrm{bpm}$ and $63-84$ beats respectively. A significant $(\mathrm{p}<0.05)$ low RHR has been observed in cricketers groups than other two groups.

A significant $(p<0.05)$ positive correlation has been found between SDNN and rMSSD (0.90) in Pearson's correlation coefficient analysis.

\section{Discussion}

Low resting HR, a type of bradycardia that has been observed in cricketers could be for training adaptation and a good cardiovascular efficiency $[4,6]$. Alteration in left ventricle may be the cause of low RHR $[3,6]$. An increase in parasympathetic tone or decreased beta-adrenergic stimulation may also be the reason of low RHR [4]. The values of rMSSD and pNN50 also support this observation [10]. ECG recorded at rest did not exhibit any arrhythmia or changes that may indicate abnormal condition of the heart. While HRV are unique and highly individual centric [4] yet a small quartile range along with the linear formation of resting HR of the cricketers indicates same type of physical activity or practice pattern as well as least intra-discipline variation. Wide fluctuation in R-R intervals of the cricketers and athlete group volunteers indicate good cardiovascular system and $\dot{\mathrm{V}} \mathrm{O}_{2}$ max which imply good aerobic capacity $[6,11]$. SDNN values of the cricketers are comparatively better than other two groups which designate a good overall HRV status. In recent years, The Cricket association of Bengal, has implemented two days cricket league in grassroots level that could also be cause of this adaptation.

The findings of resting HR of the non-athletes group are similar to the findings of Martinelli et al. [8]. This observation is also supported by the works of Catai et al. [6]. The observation of time domain parameters in HRV such as SDNN, rMSSD and pNN50 is also in agreement with the findings of Catai et al., Martinelli et al., and Nunan et al. [6, 8, 10]. The findings of resting $\mathrm{HR}$ of athletics group volunteers are relatively higher than the observation of Dixon et al., Jensen et al. and Berkoff et al. [7, 11, 12]. Therefore, the present athletics group volunteers are likely to be less physically fit as well as autonomically balanced than the Swedish middle and long distance runners (age: $25.0 \pm 3.0$ years), elite American track and field athletes (age: $24.8 \pm 4.0$ years), and Brazilian long distance runners (age: $27.4 \pm 2.6$ years).

\section{Conclusion}

From this study, it can be concluded that the resting HR of the cricketers is significantly lower than that of the athletes and non-athletes. A high level of parasympathetic dominancy at rest has been perceived in the cricketers. Cricketers have good cardiovascular efficiency and positive sign of training adaptation. The present study brings forward one significant observation that the cricketers have a low resting heart rate, a kind of bradycardia brought up by the nature of sports or the training. The table value of time domain parameters of HRV can be used as a reference for the forthcoming study.

\section{Acknowledgements}

The author acknowledge the support from UGC, Govt. of India for the SRF to Subhashis Biswas, all the volunteers who participated in the study and also thank The Cricket Association of Bengal, Nadia district sports association and West Bengal Athletics Association for their support and finally to the Vice Chancellor, RKMVERI for continuing inspiration in the work.

\section{Conflict of Interest}

The author declares that he has no competing interest.

\section{References}

[1] Hall, J. E., \& Guyton, A. C. (2011). Guyton and Hall textbook of medical physiology. Philadelphia, PA: Saunders Elsevier.

[2] Shaffer, F., \& Ginsberg, J. P. (2017). An Overview of Heart Rate Variability Metrics and Norms. Frontiers in Public Health, 5, 258. http://doi.org/10.3389/ fpubh.2017. 00258.

[3] Reimers, A. K., Knapp, G., \& Reimers, C. D. (2018). Effects of Exercise on the Resting Heart Rate: A Systematic Review and Meta-Analysis of Interventional Studies. Journal of clinical medicine, 7 (12), 503. doi: 10.3390/jcm7120503.

[4] Plews, D. J., Laursen, P. B., Stanley, J., Kilding, A. E., \& Buchheit, M. (2013). Training adaptation and heart rate variability in elite endurance athletes: opening the door to effective monitoring. Sports medicine, 43 (9), 773-781.

[5] Schneider, C., Hanakam, F., Wiewelhove, T., Döweling, A., Kellmann, M., Meyer, T. Ferrauti, A. (2018). Heart Rate Monitoring in Team Sports-A Conceptual Framework for Contextualizing Heart Rate Measures for Training and Recovery Prescription. Frontiers in physiology, 9, 639. doi: 10.3389/fphys.2018.00639.

[6] Catai, A. M., Chacon-Mikahil, M. P. T., Martinelli, F. S., Forti, V. A. M., Silva, E., Golfetti, R.,...\& Milan, L. A. (2002). Effects of aerobic exercise training on heart rate variability during wakefulness and sleep and cardiorespiratory responses of young and middle-aged healthy men. Brazilian Journal of Medical and Biological Research, 35 (6), 741-752.

[7] Dixon, E. M., Kamath, M. V., McCartney, N., \& Fallen, E. L. (1992). Neural regulation of heart rate variability in endurance athletes and sedentary controls. Cardiovascular research, 26 (7), 713-719.

[8] Martinelli, F. S., Chacon-Mikahil, M. P. T., Martins, L. E. B., Lima-Filho, E. C., Golfetti, R., Paschoal, M. A., \& GalloJunior, L.. (2005). Heart rate variability in athletes and nonathletes at rest and during head-up tilt. Brazilian Journal of Medical and Biological Research, 38 (4), 639-647.2 https://dx.doi.org/10.1590/S0100-879X2005000400019

[9] Task Force of the European Society of Cardiology. (1996). Heart rate variability, standards of measurement, physiological interpretation, and clinical use. Circulation, 93, 1043-1065. 
[10] Nunan, D., Sandercock, G. R., \&Brodie, D. A. (2010). A quantitative systematic review of normal values for short-term heart rate variability in healthy adults. Pacing and clinical electrophysiology, 33 (11), 1407-1417.

[11] Jensen Urstad, K., Saltin, B., Ericson, M., Storck, N., \& Jensen-Urstad, M. (1997). Pronounced resting bradycardia in male elite runners is associated with high heart rate variability. Scandinavian journal of medicine \& science in sports, 7 (5), 274-278.
[12] Berkoff, D. J., Cairns, C. B., Sanchez, L. D., \& Moorman III, C. T. (2007). Heart rate variability in elite American trackand-field athletes. Journal of strength and conditioning research, 21 (1), 227. 